\title{
Comparing effects of bovine Streptococcus and Escherichia coli mastitis on impaired reproductive performance
}

\author{
Y. Lavon, ${ }^{1 *}$ G. Leitner ${ }^{2}$ Y. Kressel, ${ }^{3}$ E. Ezra, ${ }^{1}$ and D. Wolfenson ${ }^{3}$ \\ ${ }^{1}$ Israel Cattle Breeders' Association, Caesarea 38900, Israel \\ ${ }^{2}$ Mastitis Laboratory, the Veterinary Institute, Bet Dagan 50250, Israel \\ ${ }^{3}$ Faculty of Agriculture, Food and Environment, the Hebrew University, Rehovot 76100, Israel
}

\section{ABSTRACT}

In 2 epidemiological studies, we evaluated the effect of mastitis induced by gram-positive Streptococcus and gram-negative Escherichia coli on impaired reproductive performance in lactating Holstein cows. In the first study, 52,202 cows from 178 dairy farms throughout Israel were divided into groups based on infection before first artificial insemination (AI) with Streptococcus or E. coli, 3 groups with elevated somatic cell count (SCC) without infection by those pathogens [low SCC $(200-400) \times 10^{3}$ cell $/ \mathrm{mL}$; medium SCC $(401-1,000) \times$ $10^{3} \mathrm{cell} / \mathrm{mL}$; high $\left.\mathrm{SCC},>1,000 \times 10^{3} \mathrm{cell} / \mathrm{mL}\right]$, and uninfected controls. Pregnancy per first AI (P/1stAI) and pregnancy rate at $300 \mathrm{~d}$ in milk (PREG 300) were analyzed by the GLIMMIX procedure (SAS); number of $\mathrm{AI}$ per pregnancy $(\mathrm{AI} / \mathrm{P})$, days open, and rest days (calving to first AI) were analyzed by the MIXED procedure (SAS Institute Inc., Cary, NC). Values of $\mathrm{P} /$ 1stAI were similarly low for Streptococcus and E. coli (27-28\%) versus $42 \%$ in controls; PREG 300 was lower for Streptococcus $(76 \%)$ than for E. coli $(79 \%)$ versus $88 \%$ for uninfected controls and a mean $83 \%$ for the elevated SCC groups. Days open and number of AI/P were higher than in controls and similar in Streptococcus and E. coli groups. The second study included 778 cows on 6 dairy farms; the cows were infected before first AI by Streptococcus or E. coli or uninfected. Resumption of cyclicity was determined by an automated activity-monitoring system, and data were sorted by time of infection before or after cyclicity resumed. The Streptococcus group had lower $\mathrm{P} / 1$ stAI before and after cyclicity (26 and $27 \%$, respectively) than the $E$. coli group (31 and 34\%, respectively) and uninfected

Received March 24, 2019

Accepted July 11, 2019.

*Corresponding author: yaniv@icba.co.il controls (42\%). Notably, PREG 300 in the Streptococcus group before $(73 \%)$ and after $(67 \%)$ cyclicity was much lower than for the E. coli group (85 and 93\%, respectively) and the controls (95\%). A marked rise in day of cyclicity resumption $(\sim 80 \mathrm{~d})$ was observed in cows that were infected early on. Number of $\mathrm{AI} / \mathrm{P}$ was higher in the mastitic groups than in uninfected controls. Uterine disease postpartum, although more prevalent among Streptococcus cows, did not substantially alter the larger reduction in P/1stAI and PREG 300 in Streptococcus versus E. coli cows. Thus, longterm Streptococcus-induced mastitis disrupted fertility more than short-term acute E. coli-induced mastitis, resulting in a much higher percentage of Streptococcus cows in late lactation that did not conceive due to reproduction failure.

Key words: mastitis, pathogen-specific, fertility, reproduction

\section{INTRODUCTION}

Mastitis and reproductive failure are the main disorders responsible for economic losses in modern dairy farms. Incidence of both mastitis and reproductive failure due to genetic selection and increased milk production as part of intensive management is on the rise. New evidence indicates an association between mastitis and reproductive failure that is due not only to their common foundation of poor management but also to a direct influence of mastitis on reproduction (Hansen et al., 2004; Lavon et al., 2010; Hertl et al., 2014).

Gram-negative $(\mathbf{G}-)$ Escherichia coli is a common cause of mastitis in dairy cows worldwide (Hogan and Smith, 2003), as well as the leading cause of the disease in well-managed dairy farms (Bradley and Green, 2001). Escherichia coli often causes clinical mastitis, with clear signs of inflammation in the affected gland that range from mild to severe (Burvenich et al., 2003). Streptococcus agalactiae, another major bacteria involved in mastitis worldwide, is no longer a problem in the Israeli 
dairy industry because of a successful eradication program. However, the occurrence of gram-positive $(\mathbf{G}+)$ Streptococcus dysgalactiae and Streptococcus uberis has been on the rise in recent years and is responsible for 7 to $8 \%$ of clinical and subclinical mastitis (Seegers et al., 2003; Halasa et al., 2007; Lundberg et al., 2014; Levison et al., 2016). Worldwide, the prevalence of both clinical and subclinical forms of mastitis is $\sim 15 \%$. Streptococcus uberis is more common in countries such as the United Kingdom (Bradley, 2002; Bradley et al., 2007) and Australia (McDougall et al., 2004; Charman et al., 2013), while Strep. dysgalactiae is more common in Nordic countries, such as Norway and Sweden (Østerås et al., 2006; Ericsson Unnerstad et al., 2009), and CNS in Finland (Vakkamäki et al., 2017). Bacterial penetration into the mammary gland through the teat canal can occur prepartum and throughout lactation. Whereas some studies suggest that Strep. dysgalactiae is a contagious pathogen that spreads from cow to cow (Barkema et al., 1999), others suggest that it is common in the environment (Wang et al., 1999). In contrast, Strep. uberis is considered to be an environmental pathogen (Abureema et al., 2014). Several studies have reported lower conception rates in mastitic cows; increased number of AI per conception (Schrick et al., 2001; Santos et al., 2004; Lavon et al., 2011a); disorders associated with the estrous cycle (Huszenicza et al., 2005), follicle development (Lavon et al., 2010), and hormone secretion (Lavon et al., 2011b); and impaired oocyte competence (Soto et al., 2003; Asaf et al., 2013) and embryo development (Hansen et al., 2004). An association has been noted between the increasing number of AI per conception and the increased incidence of mastitis caused by Strep. dysgalactiae and Strep. uberis. Given that time to conceive has economic value on highly intensive dairy farms (De Vries, 2006), this observation required scientific evaluation. Here we analyzed respective data on mastitis and reproductive performance, taken from the recording program of the Israeli Cattle Breeders' Association, and tested for correlations. Data included, among other variables, pregnancy per first AI ( $\mathbf{P} / \mathbf{1}$ stAI $)$; pregnancy rate at 300 DIM (PREG 300), which determines, to a great extent, the culling rate of cows; days open; and number of AI per pregnancy (AI/P). Our specific objective was to compare reproductive performance of cows infected by either G-Escherichia coli or G+ Streptococcus spp., with an emphasis on the timing of infection of the 2 bacteria relative to resumption of cyclicity. We hypothesized that G+ Streptococcus, which induces long-term, chronic mastitis, would be more detrimental to reproduction than short-term $\mathrm{G}-E$. coli mastitis.

\section{MATERIALS AND METHODS}

\section{Study Design}

Two epidemiological experiments (Exp.) were conducted to compare the detrimental effects on fertility of the 2 most prevalent types of pathogen-induced mastitis: G+ Streptococcus and G-E. coli. One study involved a large data set collected from 178 farms, while the other was a smaller refined study.

The Large Study (Exp. 1). We used data from 2011 to 2013 from the milk-recording program of the Israeli Cattle Breeders' Association (Israeli Herd Book), including mastitis identification bacteriology from the National Service for Udder Health and Milk Quality. For bacteriological examination, $10 \mu \mathrm{L}$ of each milk sample was inoculated onto blood agar (5\% washed sheep red blood cells) and MacConkey agar plates (BactoAgar, Becton Dickinson, Franklin Lakes, NJ). Plates were incubated at $37^{\circ} \mathrm{C}$ and examined for bacterial growth after 18 and $42 \mathrm{~h}$. This procedure was based on the Laboratory Handbook on Bovine Mastitis, National Mastitis Council Inc. (Adkins et al., 2017) Milk samples were collected by certified technicians during monthly visits to the farms and analyzed for SCC in a Fossomatic 360 (Foss Electric, Hillerød, Denmark). Records from 52,202 (27,391 primiparous and 24,811 multiparous) Holstein cows from 178 commercial dairy farms located throughout the country were analyzed. Samples from cows that were sent by the farmer for bacteriological identification due to a clinical udder infection event or high SCC $\left(>10^{6}\right.$ cell $\left./ \mathrm{mL}\right)$ recorded in the monthly milk samples routinely taken in the commercial herds were considered. From these cows, 15,854 samples were collected before first AI. The cows were divided into 5 groups: (1) Streptococcus isolated $(\mathrm{n}=$ $2,075)$; (2) E. coli isolated ( $\mathrm{n}=3,478)$; and 3 groups that were sorted according to SCC levels, including most of the remaining cows, mostly infected with CNS or no bacteria found: (3) low SCC of (200 to 400) $\times 10^{3}$ cell $/ \mathrm{mL}(\mathrm{n}=3,509)$; (4) medium SCC of $(401$ to 1,000$)$ $\times 10^{3} \mathrm{cell} / \mathrm{mL}(\mathrm{n}=1,961)$; and $(5)$ high $\mathrm{SCC}>1,000$ $\times 10^{3} \mathrm{cell} / \mathrm{mL}(\mathrm{n}=4,831)$. A very small number of cows that were identified with Staphylococcus aureus or Corynebacterium bovis were excluded from the study due to the national policy of immediate culling of cows with these isolates.

A sixth group served as the control group $(\mathrm{n}=36,348)$ from the same commercial farms, including cows that had $\mathrm{SCC}<200 \times 10^{3}$ cell $/ \mathrm{mL}$ in the first 2 to 3 routine monthly milk samples taken before first AI. The cutoff value of $200 \times 10^{3}$ cell $/ \mathrm{mL}$ was confirmed after pre- 
analyses (see Data Analyses section) of $<100 \times 10^{3}$ and $<200 \times 10^{3} \mathrm{cell} / \mathrm{mL}$, which showed no significant differences in any of the parameters tested. This cutoff is commonly used for uninfected cows serving as controls (Schukken et al., 2003). It should be noted, however, that cows with chronic subclinical mastitis infection in one gland with CNS can have a SCC $<200 \times 10^{3}$ cell/ $\mathrm{mL}$. Thus, the control cows in the present study may have included infected cows, but the infections probably did not involve E. coli or Streptococcus. Although milk samples from control cows were not analyzed for bacteriology, their low SCC was highly correlated with health status of uninfected individuals.

The Refined Study (Exp. 2). Data from 6 farms were studied in more detail. Each cow infected with either Streptococcus or E. coli and noninfected controls from the same farms were analyzed using online computer data (AfiLab equipment, S.A.E. Afikim, Israel) recorded at each farm and with the aid of the NOA program (Herd Management Program, Israel Cattle Breeders Association, Caesarea, Israel). Several variables were included in the analysis. The determination of date of infection was relatively simple for the $E$. coli cases because the bacteria disappear from milk samples within a few days after infection. For cows found to have a Streptococcus isolate, the estimated date of infection was set as the date on which the first postpartum routine monthly milk sample had SCC $>200 \times$ $10^{3} \mathrm{cell} / \mathrm{mL}$. This approach was based on the finding that cows infected with Streptococcus exhibit gradual and long-term elevation of SCC for several weeks until peak SCC is reached (de Haas et al., 2002). The date of resumption of cyclicity was determined by using AfiLab activity charts. Cyclicity was determined when at least 2 sequential peaks of activity typical for day of estrus were recorded at 18- to 25-d intervals; day of cyclicity was defined as the first elevation of the activity chart. In a few cows, an early, single peak elevation of activity occurred around d 15 to 25 postpartum, but it was not followed by a second peak elevation of activity 18 to 25 d later. Instead, a lengthy period of several weeks followed without any sign of estrus activity. This pattern was not considered to be associated with initiation of cyclicity. We also included metabolic and uterine disease in the analysis, with the former including mainly ketosis. Uterine health status postpartum included presence or absence of retained fetal membranes (for more than $24 \mathrm{~h}$ after calving), and endometritis (enlarged uterus with inflammation and purulent vaginal discharge). Accordingly, 2 subgroups of Streptococcus cows and 2 subgroups of $E$. coli cows were established, according to infection recorded before or after cyclicity (before first AI). As in Exp. 1, cows that had SCC
$<200 \times 10^{3}$ cell $/ \mathrm{mL}$ milk were considered uninfected, control cows.

Additional recorded data included herd, lactation number, season of AI, and year of calving, and BCS at calving and at peak milk yield (50-60 DIM). In both experiments, routine AI was performed by professional technicians following detection of estrus, and pregnancy was confirmed by rectal palpation 40 to $50 \mathrm{~d}$ after AI. Cows that were not diagnosed as pregnant were recorded as not pregnant.

\section{Data Analyses}

Experiments 1 and 2 were analyzed independently. A multivariable model was designed with a logistic model statement using the GLIMMIX procedure of SAS (version 9.2, SAS Institute, Cary, NC), with first insemination outcome P/1stAI and PREG 300, as previously described (Lavon et al., 2011a, 2016). In addition, we used PROC MIXED procedure of SAS with continuous variables: rest days (calving to first $\mathrm{AI}$ ), days open, resumption of cyclicity, and number of $\mathrm{AI} / \mathrm{P}$ as the dependent variable.

In Exp. 1 , the entire data set $(\mathrm{n}=52,202)$ was analyzed with the general form

$$
\begin{gathered}
\text { P/1stAI or PREG } 300=\text { Intercept }+ \text { Herd } \\
+ \text { Calving_year }+ \text { Season }+ \text { Lactation number } \\
+ \text { Group }+ \text { AI_Year }+ \text { Season } \times \text { Group } \\
+ \text { Lactation number } \times \text { Group }+ \text { error },
\end{gathered}
$$

where $\mathrm{P} / 1$ stAI or PREG $300=\ln \mathrm{P} /(1-\mathrm{P}), \mathrm{P}=$ probability of pregnancy; Herd $=178$ dairy farms; Season $=\mathrm{AI}$ in summer (including fall; July to November) or winter (including spring; December to June); Lactation number $=1,2,3$, or more lactations; Group $=6 \mathrm{ex}-$ perimental groups (as described earlier); and AI_Year = year of AI (2011-2013). All variables except Herd were considered fixed effects. Herd was included as a random effect.

In Exp. 2, the entire data set $(\mathrm{n}=778)$ was analyzed with the general form

$$
\begin{gathered}
\text { P/1stAI or PREG } 300=\text { Intercept }+ \text { Group + Herd } \\
+ \text { Lactation number + Season + Uterine disease } \\
+ \text { BCS }+2 \text {-way Group interactions + error }
\end{gathered}
$$

where $\mathrm{P} / 1$ stAI or PREG $300=\ln \mathrm{P} /(1-\mathrm{P}), \mathrm{P}=$ probability of pregnancy; Group $=3$ experimental groups (as described earlier); Herd $=6$ dairy farms; Lactation 
number $=1,2,3$, or more lactations; Season $=\mathrm{AI}$ in summer and fall (July to November) or winter and spring (December to June); Uterine disease $=$ uterine health status postpartum; and BCS at calving divided into 2 categories, $\geq 3.25$ or $<3.25$. All variables were considered fixed effects.

In addition to the above analysis of Exp. 2, 2 separate analyses were performed for E. coli and Streptococcus groups that were infected either before or after resumption of cyclicity. Control, E. coli, and Streptococcus groups were included in each analysis. For day of cyclicity, rest day, open day, and number of $\mathrm{AI} / \mathrm{P}$, the PROC MIXED procedure was applied; whereas, for $\mathrm{P} / 1$ stAI and PREG 300, the GLIMMIX procedure was applied. These additional analyses enabled comparing not only each of the mastitis groups to the uninfected control group, but also the 2 mastitis groups to one another before or after resumption of cyclicity, separately. Probability of conception for the level of a specific variable included in the models was based on least squares means values, and $P$-values were adjusted by the Bonferroni correction for multiple comparisons, as described previously (Lavon et al., 2011a, 2016).

\section{RESULTS}

\section{Experiment 1-Large Study}

In Exp. 1, we compared the reproductive performance of Streptococcus and E. coli groups and an additional 3 groups with low, medium, and high SCC elevation. All cows that were tested for IMI, regardless of the bacteria isolated, exhibited significantly lower probability of $\mathrm{P} / 1$ stAI than uninfected controls. For the Streptococcus group, $\mathrm{P} / 1$ stAI was lower by $26.7 \%(0.104 / 0.389)$ and that of the $E$. coli group by $19.5 \%$, compared with the reference value of uninfected controls $(P<0.05$, Table 1). Accordingly, means of P/1stAI of uninfected, Streptococcus, and E. coli groups were $42.3,26.9$, and $28.1 \%$, respectively, and among the 3 elevated SCC groups, the medium SCC group exhibited the lowest P/1stAI (Figure 1).

Regardless of the bacteria isolated, all cows tested for mastitis exhibited significantly lower probability of PREG 300 than uninfected controls. Cows that were infected with Streptococcus had the lowest values, followed by $E$. coli-infected cows $(E$. coli: $0.070 / 0.833=$ $-8.4 \%$; LSM diff. divided by LSM of the reference value of uninfected controls; $P<0.01$, Table 1). As with $\mathrm{P} / 1$ stAI, among the elevated SCC groups, the medium SCC group exhibited the lowest probability of PREG $300(P<0.01$, Table 1$)$. Accordingly, mean PREG 300 for the Streptococcus group was the lowest (88\% vs. 76 and $79 \%$ for uninfected versus Streptococcus and E. coli, respectively, $P<0.01$, Figure 1), and mean PREG 300 of the medium SCC group was the lowest $(80.1 \%)$ among the 3 elevated SCC groups (Figure 1). Lactation number and season interactions with group did not differ (results not shown).

Table 1. Generalized mixed model used to estimate the effect of 2 bacterial types, Escherichia coli and Streptococcus, and 3 levels of SCC elevation before first AI on probability of pregnancy rate at 300 DIM (PREG 300) and probability of conception from first AI (P/1stAI), in 52,202 cows from 178 commercial dairy farms in 2011 to 2013 (Exp. 1)

\begin{tabular}{|c|c|c|c|c|c|c|c|c|}
\hline Variable & Level & $\mathrm{n}$ & \multicolumn{3}{|c|}{ PREG 300} & \multicolumn{3}{|c|}{$\mathrm{P} / 1$ stAI } \\
\hline Parity & $\begin{array}{l}3+ \\
2 \\
1\end{array}$ & $\begin{array}{r}8,483 \\
16,328 \\
27,391\end{array}$ & $\begin{array}{l}-\overline{-} \\
0.113^{*}\end{array}$ & 0.742 & $\begin{array}{l}- \\
0.006 \\
0.005\end{array}$ & $\begin{array}{l}-\overline{0.030} \\
0.105^{*}\end{array}$ & 0.261 & $\begin{array}{l}-\overline{0.008} \\
0.008\end{array}$ \\
\hline Season & $\begin{array}{l}\text { Winter } \\
\text { Summer }\end{array}$ & $\begin{array}{l}33,570 \\
18,632\end{array}$ & $-\overline{-001}$ & 0.793 & $\overline{0.003}$ & $-\overline{0.102} *$ & 0.341 & $\overline{0.005}$ \\
\hline Year & $\begin{array}{l}2013 \\
2012 \\
2011\end{array}$ & $\begin{array}{r}9,701 \\
21,590 \\
20,911\end{array}$ & $\begin{array}{l}-\overline{1} \\
0.135^{*}\end{array}$ & 0.7 & $\begin{array}{l}\overline{0.004} \\
0.004\end{array}$ & $\begin{array}{c}-\overline{0.067^{*}} \\
-0.053^{*}\end{array}$ & 0.34 & $\begin{array}{l}\overline{-} \\
0.005 \\
0.005\end{array}$ \\
\hline
\end{tabular}

${ }^{1}$ Differences in parameters' least squares means values (LSM diff.) are deviations from the reference (Ref.) levels.

${ }^{2}$ Reference levels of the variables correspond to probability of PREG 300 or probability of P/1stAI for each variable.

${ }^{3}$ Control cows had SCC $<200,000$ cell $/ \mathrm{mL}$ before first AI; E. coli group: cows that were sampled and diagnosed with E. coli before first AI; Strep. spp. group: cows that were sampled and diagnosed with Streptococcus spp. before first AI; SCC low: $(200-400) \times 10^{3}$ cell $/ \mathrm{mL}$; SCC medium: $(401-1,000) \times 10^{3}$ cell $/ \mathrm{mL}$; SCC high: $>1,000 \times 10^{3} \mathrm{cell} / \mathrm{mL}$, infected with CNS, or no bacteria found, before first AI.

${ }^{*} P<0.01$ : values differ within a column; lactation number and season interactions with group did not differ. 

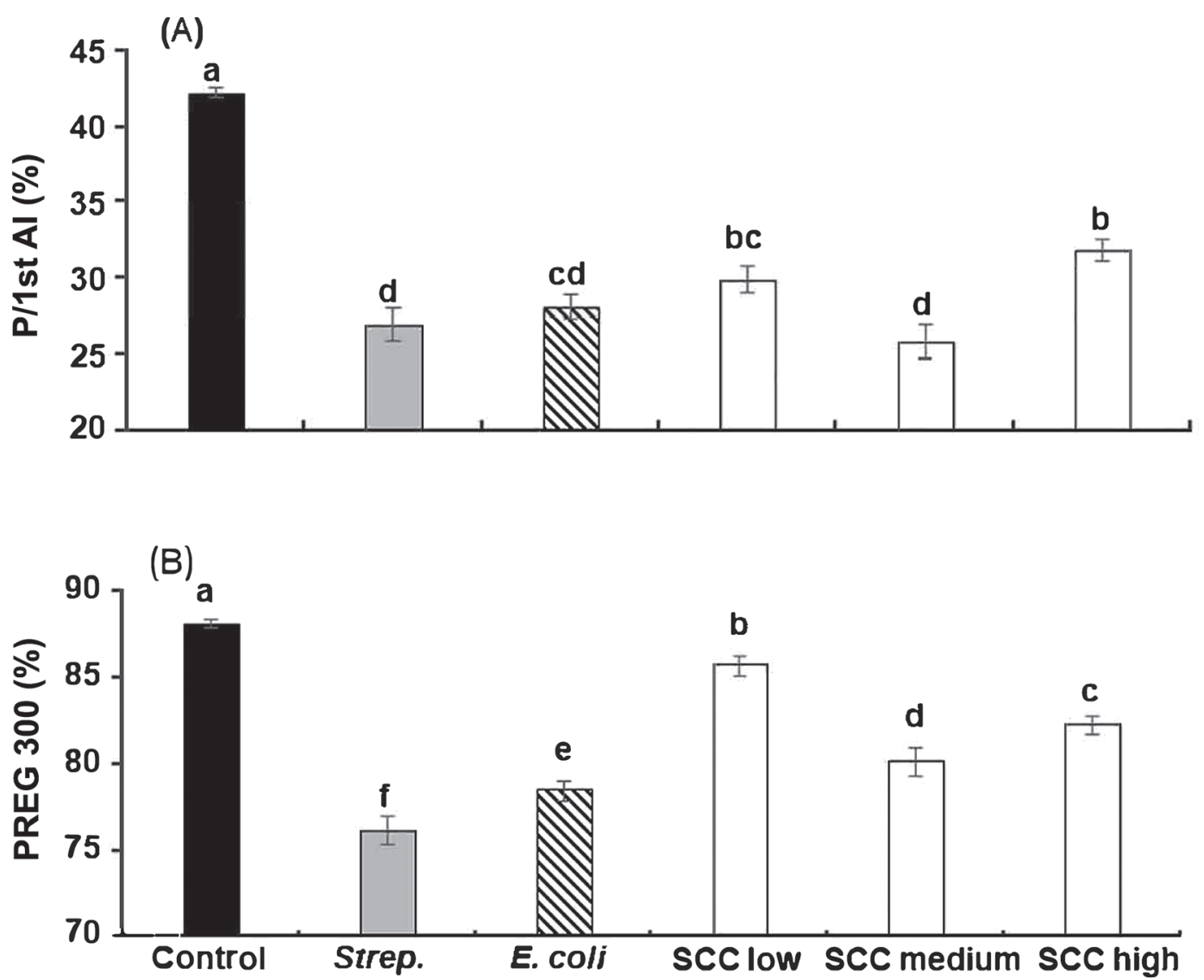

Figure 1. Effect of pathogen-specific mastitis due to Streptococcus (Strep.; $\mathrm{n}=2,075)$ and Escherichia coli $(\mathrm{n}=3,478)$ and effect of elevated SCC (3 groups: low, $\mathrm{n}=3,509$; medium, $\mathrm{n}=1,961$; high, $\mathrm{n}=4,831)$ before first AI, versus uninfected controls ( $\mathrm{n}=36,348$; with SCC levels $<200,000)$, on (A) pregnancy per first AI (P/1stAI) and (B) pregnancy rate at 300 DIM (PREG 300) (Exp. 1). Data are presented as mean \pm SEM. Different letters (a-f) denote significant differences at $P<0.01$.

Rest days for all 5 mastitis groups (Streptococcus, E. coli, and the 3 elevated SCC groups) did not differ and were about $5 \mathrm{~d}$ higher than for controls (Figure 2, $P$ $<0.05)$. Similarly, days open for all 5 mastitis groups were higher than for uninfected controls (Figure 2, $P<$ 0.05); those of the Streptococcus and E. coli groups were similarly higher than controls (138 vs. $120 \mathrm{~d}$ ), and the medium SCC group had the highest days open (146 d). Similar to days open, the number of AI/P was higher for all 5 mastitis groups than for controls; those of the Streptococcus and E. coli groups were similarly high (2.55 and 2.1, respectively, Figure 2, $P<0.05$ ), and the number of $\mathrm{AI} / \mathrm{P}$ for the medium SCC group was 2.75 $(P<0.05$, Figure 2).

\section{Experiment 2-Refined Study}

In Exp. 2, 15 and $7 \%$ of the cows identified with Streptococcus and E. coli, respectively, by the laboratory were not supported as mastitic cows by the online computer data and the herd management program; namely, they did not show typical alterations of milk production and milk conductivity. These results probably represented contaminated samples. Therefore, the corresponding cows were removed from the study. Of the cows infected with Streptococcus, most were infected before resumption of cyclicity, similar to the cows infected with $E$. coli (Table 2). The actual mean values for all parameters are shown in Figures 3 and 4. None of the 2-way interactions with experimental groups was statistically significant.

Overall, probability of $\mathrm{P} / 1$ stAI was $35.7 \%$ lower for Streptococcus and $26.2 \%$ lower for E. coli cows compared with uninfected controls; calculations yielded rates of 42,27 , and $31 \%$, respectively $(P<0.05$, Table 2 ). Values of Streptococcus and E. coli groups did not differ. Similarly, overall PREG 300 was $23.2 \%$ lower for Streptococcus and only $10.5 \%$ lower for E. coli groups compared with uninfected controls; calculation yielded rates of 95,73 , and $85 \%$, respectively $(P<0.05$, Table $2)$; values of Streptococcus and E. coli groups differed $(P<0.05)$. 
When infection occurred before cyclicity, P/1stAI was lower in Streptococcus than in E. coli cows; both differed from controls $(P<0.05)$ but did not differ significantly from each other (Table 2 , Figure 3 ). After cyclicity, $\mathrm{P} / 1$ stAI was similarly $(P<0.05)$ lower for the Streptococcus group and tended $(P<0.08)$ to be lower for the $E$. coli group compared with uninfected controls (Table 2, Figure 3). The 2 infected groups did not differ.
The most important findings in this study involved PREG 300. When infection occurred before resumption of cyclicity, both infected groups differed from controls $(P<0.05)$ but not from each other (Table 2, Figure 3), although PREG 300 was lower $(73 \%)$ for the Streptococcus versus E. coli (85\%) groups. After resumption of cyclicity, PREG 300 for the Streptococcus group was as low as $67 \%(P<0.05)$, while that of the E. coli group was much higher (93\%). Streptococcus and E. coli

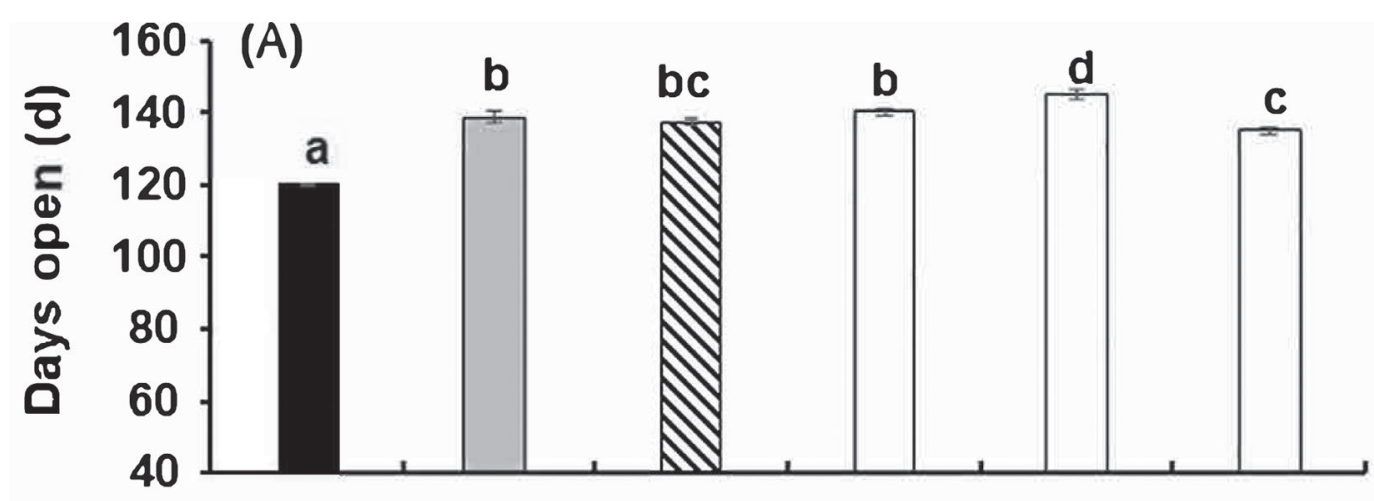

(B)
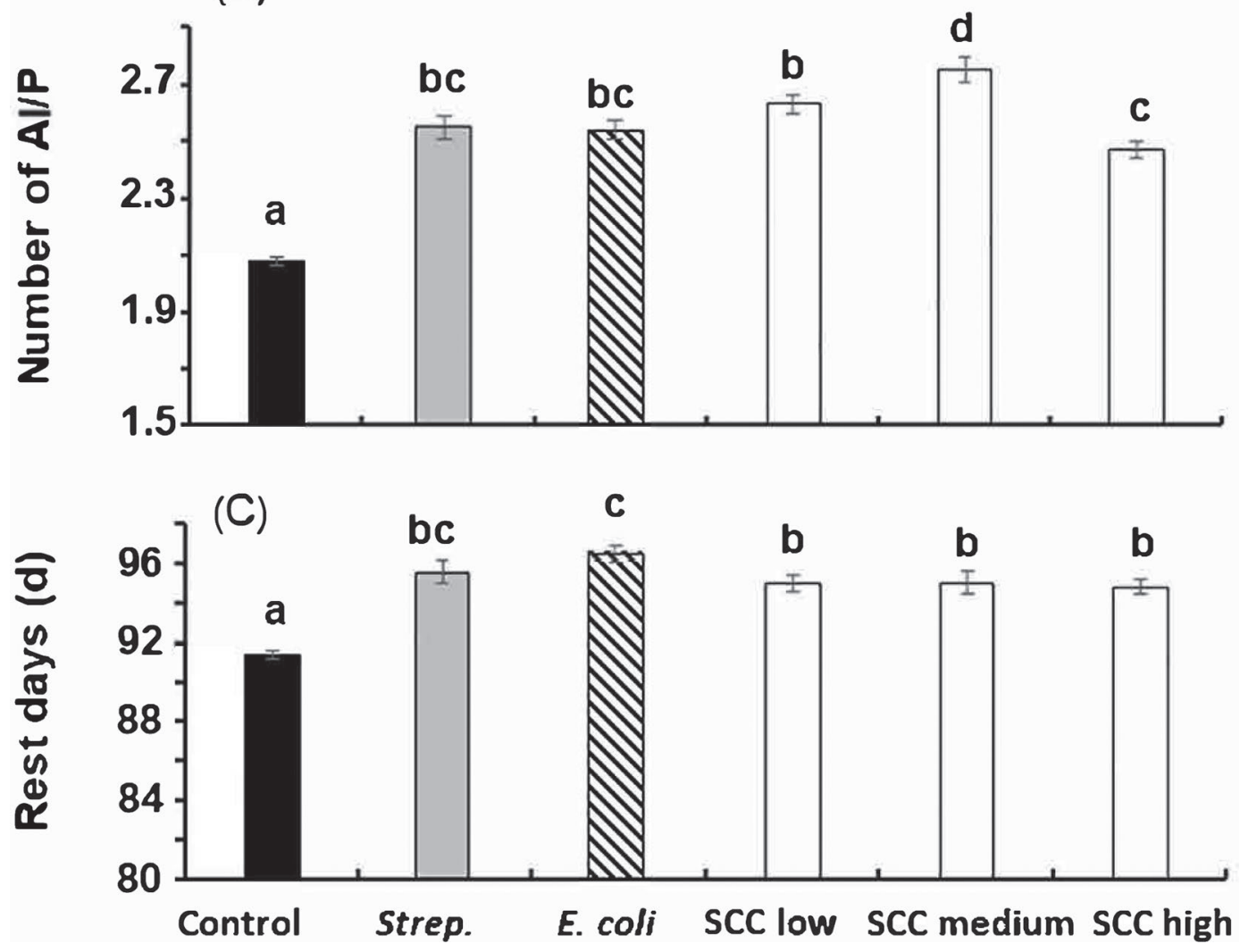

Figure 2. Effect of pathogen-specific mastitis due to Streptococcus (Strep.; $\mathrm{n}=2,075)$ and Escherichia coli $(\mathrm{n}=3,478)$ and effect of elevated SCC (3 groups: low, $\mathrm{n}=3,509$; medium, $\mathrm{n}=1,961$; high, $\mathrm{n}=4,831)$ before first AI, versus uninfected controls $(\mathrm{n}=36,348$; with SCC levels $<200,000)$, on (A) days open, (B) number of AI per pregnancy (AI/P), and (C) rest days (Exp. 1). Data are presented as mean \pm SEM. Different letters $(\mathrm{a}-\mathrm{d})$ denote significant differences at $P<0.05$. 
groups differed $(P<0.05)$, and the $E$. coli group tended to have lower values than the uninfected controls $(95 \%$, $P<0.08$, Table 2, Figure 3).

When infection occurred before resumption of cyclicity, the number of $\mathrm{AI} / \mathrm{P}$ for uninfected controls was lower than for Streptococcus and E. coli groups (2.5 vs. 3.0 and 3.4 , respectively, $P<0.05$, Figure 4 ); the latter tended to be higher than that for the Streptococcus group $(P<0.09)$. As for rest days $(P<0.03)$ and days open $(P<0.10)$, the Streptococcus group was higher or tended to be higher than controls (Figure 4); Streptococcus and E. coli groups did not differ. Resumption of cyclicity was delayed by 16 to $22 \mathrm{~d}$ in the 2 mastitis groups compared with controls $(P<0.05$, Figure 4). When infection occurred after resumption of cyclicity, the number of AI/P was only larger for $E$. coli cows relative to controls (2.95 vs. $2.38 ; P<0.03$ ). Rest days and days open were slightly higher and did not differ from controls; the 2 mastitis groups did not differ (Figure 4). Days to resumption of cyclicity were surprisingly less for E. coli and Streptococcus groups than for controls (46 and $39 \mathrm{~d}$, respectively, vs. $64 \mathrm{~d}, P$ $<0.05$, Figure 4).

Distribution of cows infected with uterine disease at parturition among uninfected, E. coli, and Streptococcus groups is presented in Table 3. Streptococcus cows had the highest proportion of uterine disease postpartum, compared with the E. coli group and the uninfected controls (Table 3). A higher proportion of metabolic disorders (mainly ketosis) postpartum was found in the Streptococcus and the E. coli groups compared with uninfected cows $(18.8,23.4$, and $12.5 \%$, respectively); however, differences between the Streptococcus and $E$. coli groups were minor (data not shown). Mean BCS at peak lactation was also similar in E. coli and Streptococcus groups and slightly lower than that of uninfected controls $(2.5,2.5$, and 2.7 , respectively; data not shown).

\section{DISCUSSION}

We analyzed the respective data for mastitis and reproductive performance from a large database - the recording program of the Israeli Cattle Breeders' Association. The major challenge in using such a database is the quality of the data. The bacteriology, sampled voluntarily by the farmers, was from cows with clinical or subclinical mastitis. For clinical mastitis, we assumed that only the infected gland had been sampled; however, $\sim 40 \%$ of these samples showed no growth or contamination. For the subclinical mastitis of cows with SCC $>10^{6}$ cell $/ \mathrm{mL}$, it was not clear in many cases whether the bacteria were from the gland with the high SCC or from another gland or glands. Consequently, the primary cause of the infected gland might not have been isolated. Moreover, only the time laboratory identification, not the time of infection, was known. Therefore, in the first analysis (Exp. 1), we assumed that E. coli and Streptococcus were from the infected glands and that all others were milk samples from infections with different bacteria; therefore, the division was based on the severity as expressed by the SCC. These

Table 2. Generalized mixed model used to estimate the effect of 2 bacterial types, ${ }^{1}$ Escherichia coli and Streptococcus, and 2 infection periods, before and after resumption of cyclicity, before first AI, on probability of pregnancy rate at 300 DIM (PREG 300) and probability of conception from first AI (P/1stAI), in 778 cows from 6 commercial dairy farms in 2011 to 2013 (Exp. 2)

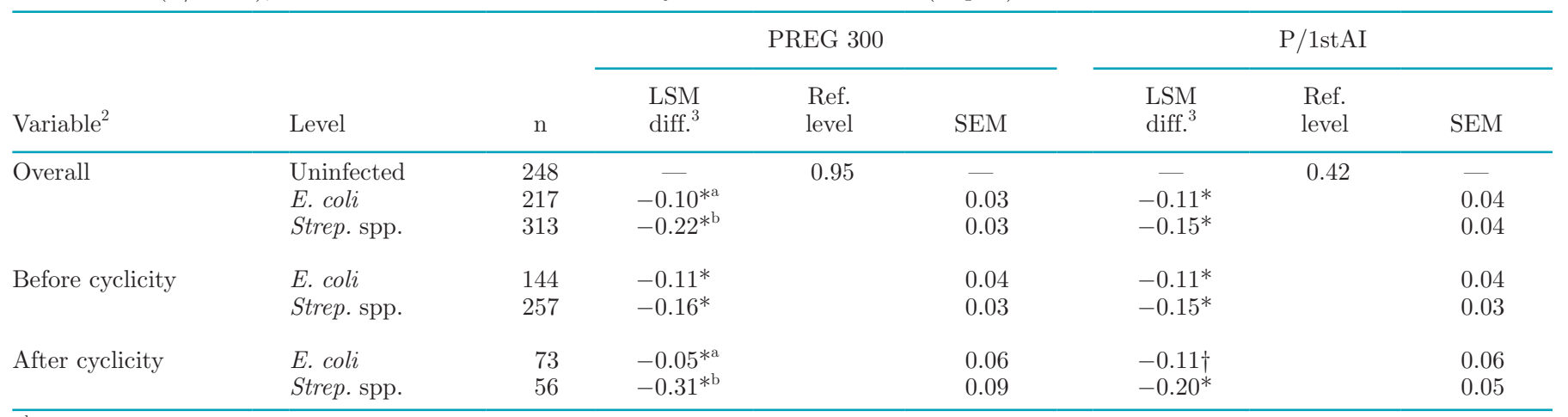

${ }^{\mathrm{a}, \mathrm{b}} P<0.05$ between bacterial types.

${ }^{1}$ Bacterial types: uninfected cows had SCC $<200,000$ cell $/ \mathrm{mL}$ before first AI; E. coli group = cows that were sampled and diagnosed with $E$. coli; Strep. group = cows that were sampled and diagnosed with Streptococcus spp. before first AI.

${ }^{2}$ Additional variables that were included in the model and are not presented: herd, lactation number, season, uterine disease, BCS, and 2-way group interactions.

${ }^{3}$ Values are deviations from the reference levels and are similar for overall, before cyclicity, and after cyclicity data sets.

$* P<0.05, \dagger P<0.08$ from the reference level. 
assumptions were proven in the second analysis (Exp. 2), which focused only on E. coli and Streptococcus. Through examination of the daily data, mainly milk production and conductivity, it was clear that in $\sim 7 \%$ of the cows that were identified with $E$. coli, the bacteria were not from an infection and the samples were probably identified as high SCC due to contamination. Among the cows that were identified with Streptococcus, $15 \%$ did not show any changes in milk production or conductivity; moreover, most of the infections occurred 30 to $60 \mathrm{~d}$ before submitting the sample to the laboratory. With regard to the control cows, cows with chronic subclinical infection in one gland can have $\mathrm{SCC}<200 \times 10^{3}$ cell $/ \mathrm{mL}$; moreover, many heifers in the first $150 \mathrm{~d}$ of lactation with $\mathrm{SCC}>80 \times 10^{3} \mathrm{cell} / \mathrm{mL}$ have CNS or Corynebacterium in one gland, and those that are truly noninfected have SCC $<40 \times 10^{3}$ cell/ mL (Bezman et al., 2015; Pyörälä and Taponen, 2009).
Thus, the control cows in this study $\left(\mathrm{SCC}<200 \times 10^{3}\right.$ cell $/ \mathrm{mL}$ ) may have included cows that were infected by bacteria other than E. coli or Streptococcus.

The major finding of this study was that clinical and subclinical mastitis are associated with lower reproductive performance. In both studies, the G+ Streptococcus had a larger deleterious effect than the $\mathrm{G}-E$. coli on reproductive performance, as shown by the more prominent reduction of P/1stAI and PREG 300. Based on Exp. 2, the practical outcome was a much larger percentage of the culling rate until 300 DIM in the Streptococcus group (about 30\%) - cows that are likely to be culled-compared with the E. coli group (about $10 \%$ ) and a minimal culling rate for uninfected controls (about 5\%).

The deleterious effect on reproduction associated with either Streptococcus- or E. coli-induced IMI is equivocal according to different studies. Some studies

(A)

$\square$ Control $\square$ Strep. DE.coli

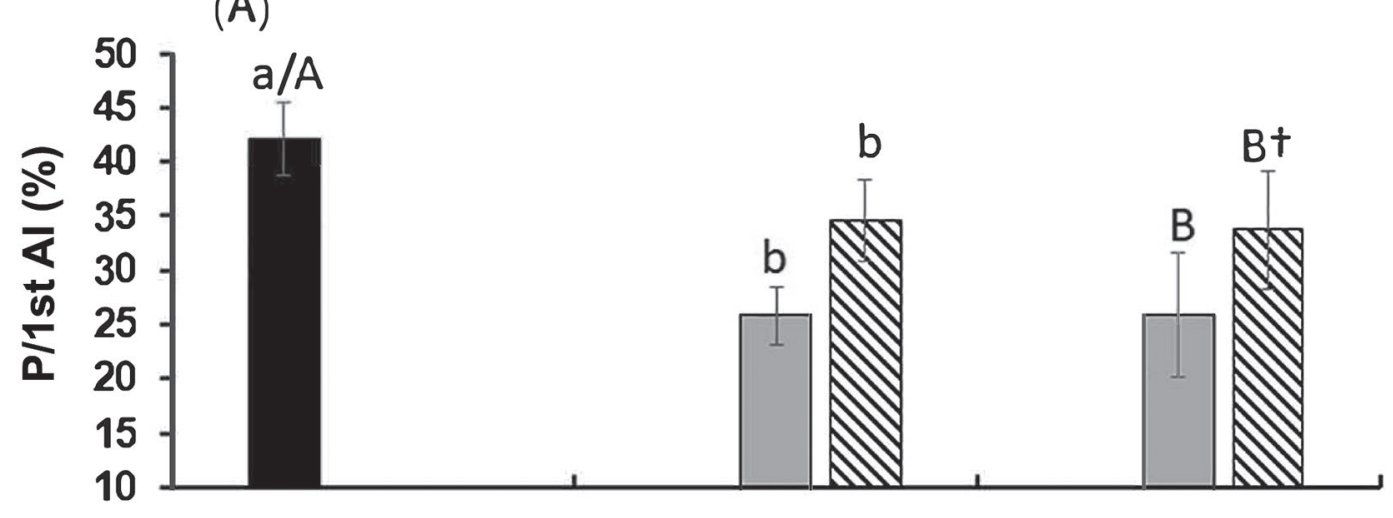

(B)

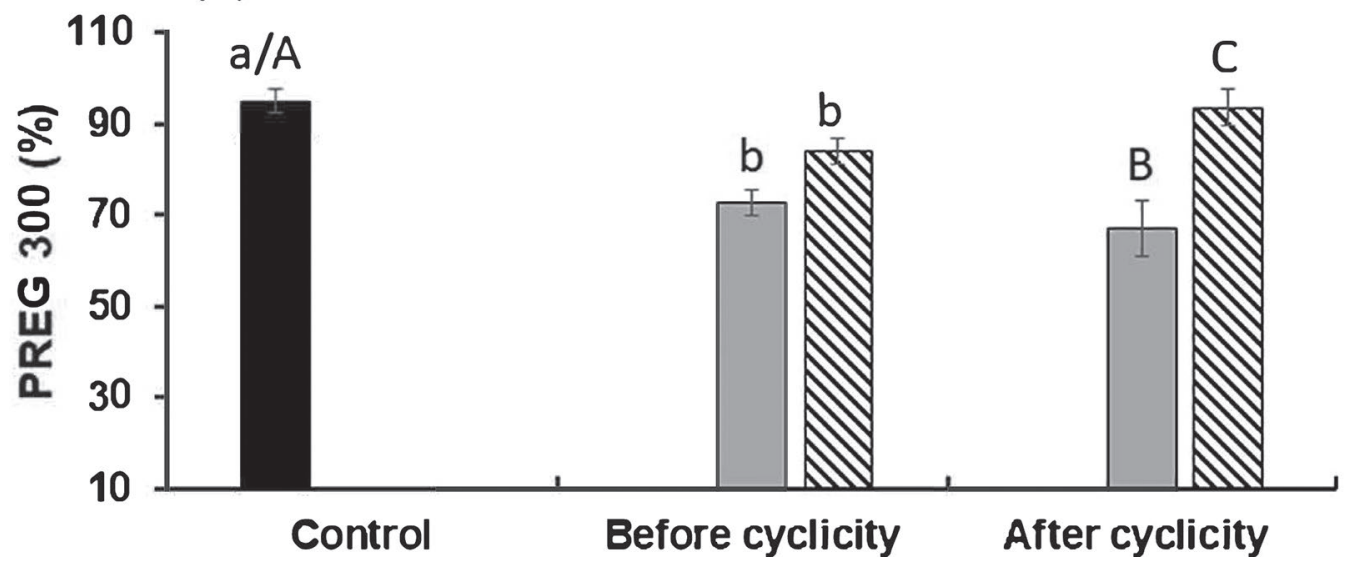

Figure 3. Effect of pathogen-specific mastitis due to Streptococcus (Strep.; $\mathrm{n}=313$ ) and Escherichia coli $(\mathrm{n}=217)$ versus uninfected controls $(\mathrm{n}=248)$, for 2 infection periods - before and after resumption of cyclicity-before first AI, on (A) pregnancy per first AI (P/1stAI) and (B) pregnancy rate at 300 DIM (PREG 300) (Exp. 2). Data of cows infected before or after resumption of cyclicity were analyzed, with uninfected controls, separately. Lowercase letters $(\mathrm{a}, \mathrm{b})$ refer to data before cyclicity and uppercase letters $(\mathrm{A}-\mathrm{C})$ to data after cyclicity, denoting significant differences at $P<0.05 ; \dagger$ indicates a tendency $(P<0.1)$ relative to controls. Data are presented as mean \pm SEM. 
Table 3. Descriptive statistics (means \pm SEM) of the effect of uterine disease postpartum among mastitic groups on reproductive performance (Exp. 2)

\begin{tabular}{|c|c|c|c|c|c|c|}
\hline Performance $^{1}$ & \multicolumn{2}{|c|}{ Control } & \multicolumn{2}{|c|}{ Streptococcus } & \multicolumn{2}{|c|}{ Escherichia coli } \\
\hline $\mathrm{P} / 1$ stAI $(\%)$ & $47 \pm 0.1$ & $40 \pm 0.1$ & $31 \pm 0.1$ & $20 \pm 0.1$ & $37 \pm 0.1$ & $29 \pm 0.1$ \\
\hline PREG $300(\%)$ & $96 \pm 0.1$ & $94 \pm 0.1$ & $76 \pm 0.1$ & $67 \pm 0.1$ & $91 \pm 0.1$ & $80 \pm 0.1$ \\
\hline Cyclicity (d) & $57 \pm 2.7$ & $66 \pm 4.4$ & $74 \pm 3.0$ & $75 \pm 3.1$ & $62 \pm 3.0$ & $74 \pm 4.2$ \\
\hline Open days & $130 \pm 4.4$ & $145 \pm 7.9$ & $139 \pm 5.4$ & $159 \pm 5.8$ & $133 \pm 5.1$ & $152 \pm 7.5$ \\
\hline
\end{tabular}

${ }^{1} \mathrm{P} / 1$ stAI $=$ pregnancy per first $\mathrm{AI} ;$ PREG $300=$ pregnancy rate at $300 \mathrm{DIM} ; \mathrm{AI} / \mathrm{P}=\mathrm{AI}$ per pregnancy.

have reported no difference between $\mathrm{G}-$ and $\mathrm{G}+$ bacteria with respect to fertility disruption (Santos et al., 2004), whereas others point to $\mathrm{G}$ - bacteria-induced IMI as being more detrimental (Hertl et al., 2010). A detailed study documenting pathogen-specific clinical mastitis showed that $\mathrm{G}-$ bacteria (mainly E. coli) depress the probability of conception more than $\mathrm{G}+$ bacteria (mainly Streptococcus; Hertl et al., 2014). A similar trend of pronounced impairment of reproduction by $\mathrm{G}$ - bacteria-induced mastitis was reported in a preliminary study in California (Moore et al., 1991). In contrast, in the current study, the G+ Streptococcus was clearly more deleterious than the $\mathrm{G}-E$. coli. It is reasonable to assume that this difference is associated with the long-term, chronic elevation of SCC induced by Streptococcus- versus E. coli-induced mastitis; the latter is characterized by a short-term elevation of SCC associated with an acute clinical event lasting only a few days. As supporting evidence, de Haas et al. (2002) previously showed that a clinical event induced by Streptococcus is characterized by elevated SCC for several weeks, both before and after peak SCC; whereas, mastitis induced by $E$. coli is not associated with elevated SCC before the peak. Obviously, the
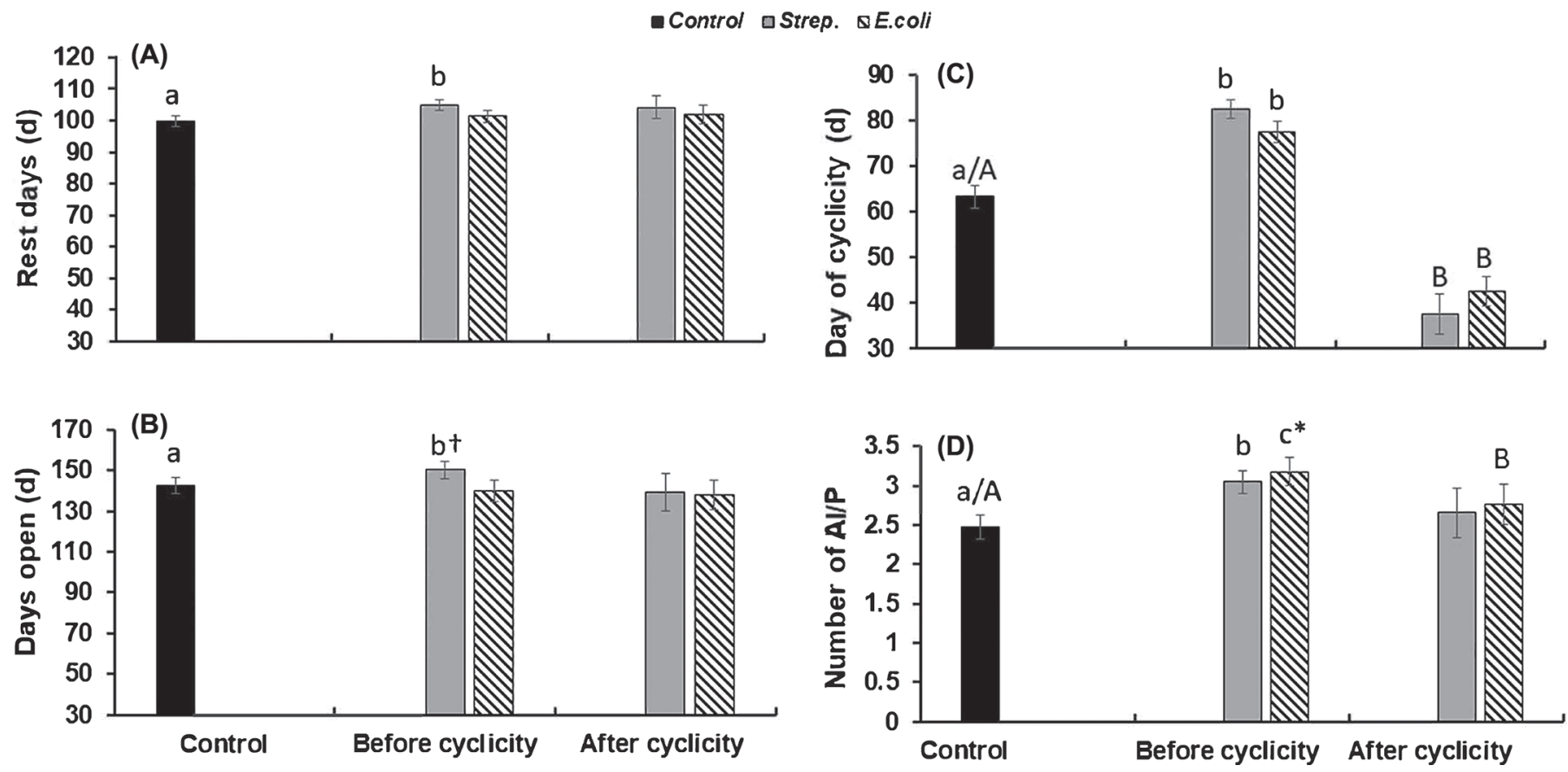

Figure 4. Effect of pathogen-specific mastitis due to Streptococcus (Strep.; $\mathrm{n}=313$ ) and Escherichia coli $(\mathrm{n}=217)$ versus uninfected controls $(\mathrm{n}=248)$, for 2 infection periods - before and after resumption of cyclicity-before first AI, on (A) rest days, (B) days open, (C) day of cyclicity, and (D) number of AI per pregnancy (AI/P) (Exp. 2). Data of cows infected before or after resumption of cyclicity were analyzed, with uninfected controls, separately. Lowercase letters $(\mathrm{a}-\mathrm{c}$ ) refer to data before cyclicity and uppercase letters (A, B) to data after cyclicity, denoting significant differences at $P<0.05 ; \dagger$ and ${ }^{*}$ indicate tendencies at $P<0.1$ relative to controls and between the 2 IMI groups, respectively. Data are presented as mean \pm SEM. 
long-term elevation of SCC induced by Streptococcus will be associated with longer elevation of cytokines and other immune agents. Several studies have shown that IMI and associated toxins alter or impair several reproductive processes over time, such as preantral follicle growth (Lavon et al., 2010, 2011b); oocyte maturation (Asaf et al., 2013); ovulation, fertilization, and embryo growth (Soto et al., 2003); corpus luteum development (Huszenicza et al., 2005); and hormone secretion (Lavon et al., 2011b). These effects, among others, consequently disrupt normal reproduction. Unlike the short-term, acute event of $E$. coli mastitis, Streptococcus-induced mastitis is more time dependent in terms of its detrimental effect on a specific reproductive process.

In Exp. 1, the group with medium SCC elevation, but not the high SCC group, exhibited the largest detrimental effect on reproduction. This finding differs from those of former studies, such as Lavon et al. (2011a), in which the level of SCC elevation before AI was directly related to the severity of the reproductive impairment. However, in the current study, the 3 elevated SCC subgroups excluded cows diagnosed as having Streptococcus or E. coli. The medium SCC group may have included more cows with long-term chronic IMI following infection by other $\mathrm{G}+$ bacteria, which, similar to the situation between Streptococcus and E. coli, may have resulted in a larger deleterious effect on reproduction.

Of interest are the substantial differences in the findings regarding low $\mathrm{P} / 1$ st AI in the current study, particularly those recorded in cows that contracted the disease early in the postpartum period, before resumption of cyclicity (Exp. 2), and those of Hertl et al. (2010, 2014) and Lavon et al. (2011a). The latter studies collectively showed that cows infected by a clinical event within about 2 wk before AI manifested the lowest conception, whereas cows infected earlier experienced only a slight negative effect from the pathogens. In contrast, the current study shows that IMI induced by either bacteria several weeks before AI, and even before resumption of cyclicity, is associated with low $\mathrm{P} / 1$ stAI and low PREG 300. We suggest that the low conception in IMI cows shown here in both Streptococcus and E. coli groups is associated with delayed resumption of cyclicity postpartum, resulting in a smaller number of cycles and less established cyclicity before AI. This phenomenon is well established and is known to be associated with low fertility in dairy cows (Thatcher and Wilcox, 1973). Indeed, in the current study, most cows contracted Streptococcus $(66.4 \%)$ or E. coli $(82.1 \%)$ early postpartum, before resumption of cyclicity. Those cows exhibited a marked delay in resumption of cyclicity (78 to $82 \mathrm{~d}$ postpartum), with first AI occurring only 1 cycle later at 104 to $101 \mathrm{~d}$, respectively. Unlike the situation here, in the studies by Hertl et al. $(2010,2014)$ and Lavon et al. (2011a), IMI-induced low conception close to AI was likely a direct effect of impairment of ovarian follicular functioning, including depressed growth, steroidogenesis, follicle-enclosed oocyte function, and possibly delayed ovulation (Lavon et al., 2010, 2011b).

Of interest is the fact that among Streptococcus cows, those infected before cyclicity exhibited more days open and a higher number of $\mathrm{AI} / \mathrm{P}$, compared with cows infected after cyclicity. These reproductive variables are based solely on cows that eventually conceived. This finding suggests that cows infected for a longer period by a G+ bacteria such as Streptococcus, which induces longer chronic, subclinical mastitis, need more time and more AI to conceive than those that contracted the disease later postpartum. This phenomenon was not evident among $E$. coli cows.

Another aspect that requires consideration is the use of an ovulation synchronization and timed AI program (Ovsynch) versus AI following natural estrus in studies that evaluate pathogen-specific mastitis effects on conception in cows. We recently showed that the probability of conception in cows with long-term, chronic subclinical mastitis, such as that induced by Streptococcus in the current study (and other pathogens), improves significantly with the timed AI program (Ovsynch) (Lavon et al., 2016). This finding might explain the larger depression of conception in cows infected by $\mathrm{G}-$ E. coli than by Streptococcus in the study by Hertl et al. (2014), in which the Ovsynch protocol was used. In the current study, in which cows underwent AI following natural estrus, the depressive effect of Streptococcus on fertility was greater than that of $E$. coli. This finding requires validation by comparative basic research on the deleterious effects of $\mathrm{G}$ - endotoxin and $\mathrm{G}+$ complex of toxins on reproductive functions. However, it is beyond the scope of this study to discuss and compare the detailed deleterious effects of $\mathrm{G}-E$. coli endotoxin on ovarian functions, which have been intensively examined in several studies (Sheldon et al., 2009), as well as of $\mathrm{G}+$ complex toxins. These latter toxins, although less widely studied, are clearly associated with severely deleterious effects on follicular growth, steroidogenesis, hormone secretion, corpus luteum function, and oocyte competence, all of which are associated with low conception (Hockett et al., 2000, 2005).

In Exp. 2, about half of the Streptococcus cows had uterine disease postpartum, compared with only about one third of the E. coli cows. As expected, cows that harbored these diseases had lower conception rates than those exhibiting mastitis only. The higher proportion of uterine disease among Streptococcus cows could arguably be associated with the lower $\mathrm{P} / 1$ stAI and 
PREG 300 in this group compared with the E. coli group. However, irrespective of the proportion of cows having uterine disease in the 2 groups, the data clearly show lower conception in Streptococcus cows that were not diagnosed with uterine disease postpartum. Notably, unlike uterine disease, the proportion of metabolic disease postpartum and BCS were quite similar among the 2 IMI groups.

\section{CONCLUSIONS}

The deleterious effects on reproduction of clinical and subclinical mastitis are associated with lower reproductive performance. Specifically, G+ Streptococcus-induced mastitis had a more pronounced effect than $\mathrm{G}-E$. coli mastitis. As a result of a much larger percentage of cows that did not conceive until 300 DIM, the culling rate of Streptococcus cows is expected to be much higher than that of $E$. coli cows and uninfected controls, causing heavy economic losses to dairy farms. According to these findings, mastitis-induced economic losses associated with reproduction failure should be taken into account.

\section{ACKNOWLEDGMENTS}

The authors thank the dairy farm managers for their help and cooperation during the study. The authors thank Adin Shwimmer (National Service for Udder Health and Milk Quality, Israeli Dairy Board, Caesarea, Israel) for his valuable help with the bacteriological data.

\section{REFERENCES}

Abureema, S., P. Smooker, J. Malmo, and M. Deighton. 2014. Molecular epidemiology of recurrent clinical mastitis due to Streptococcus uberis: Evidence of both an environmental source and recurring infection with the same strain. J. Dairy Sci. 97:285-290.

Adkins, P. R. F., J. R. Middleton, L. K. Fox, G. Pighetti, and C. P. Petersson-Wolfe. 2017. Laboratory Handbook on Bovine Mastitis. 3rd ed. National Mastitis Council, New Prague.

Asaf, S., G. Leitner, O. Furman, Y. Lavon, D. Kalo, D. Wolfenson, and Z. Roth. 2013. Effects of Escherichia coli- and Staphylococcus aureus-induced mastitis in lactating cows on oocyte developmental competence. Reproduction 147:33-43.

Barkema, H. W., Y. H. Schukken, T. J. Lam, M. L. Beiboer, G. Benedictus, and A. Brand. 1999. Management practices associated with the incidence rate of clinical mastitis. J. Dairy Sci. 82:1643-1654.

Bezman, D., L. Lemberskiy-Kuzin, G. Katz, U. Merin, and G. Leitner. 2015. Influence of intramammary infection of a single gland in dairy cows on the cow's milk quality. J. Dairy Res. 82:304-311.

Bradley, A. J. 2002. Bovine mastitis: An evolving disease. Vet. J. $164: 116-128$

Bradley, A. J., and M. J. Green. 2001. Adaptation of Escherichia coli to the bovine mammary gland. J. Clin. Microbiol. 39:1845-1849.

Bradley, A. J., K. A. Leach, J. E. Breen, L. E. Green, and M. J. Green. 2007. Survey of the incidence and etiology of mastitis on dairy farms in England and Wales. Vet. Rec. 160:253-257.
Burvenich, C., V. Van Merris, J. Mehrzad, A. Diez-Fraile, and L. Duchateau. 2003. Severity of $E$. coli mastitis is mainly determined by cow factors. Vet. Res. 34:521-564.

Charman, N., R. Dyson, A. Hodge, N. Robertson, and S. Chaplin. 2013. A survey of mastitis pathogens in South-Eastern Australian dairy industry. Pages 18-22 in Proc. Countdown Symposium, Melbourne, Australia. Countdown Symposium \& Dairy Australia.

de Haas, Y., H. W. Barkema, and R. F. Veerkamp. 2002. The effect of pathogen-specific clinical mastitis on the lactation curve for somatic cell count. J. Dairy Sci. 85:1314-1323.

De Vries, A. 2006. Economic value of pregnancy in dairy cattle. J. Dairy Sci. 89:3876-3885.

Ericsson Unnerstad, H., A. Lindberg, K. P. Waller, T. Ekman, K. Artursson, M. Nilsson-Ost, and B. Bengtsson. 2009. Microbial aetiology of acute clinical mastitis and agent-specific risk factors. Vet. Microbiol. 137:90-97.

Halasa, T., K. Huijps, O. Østerås, and H. Hogeveen. 2007. Economic effects of bovine mastitis and mastitis management: A review. Vet. Q. 29:18-31.

Hansen, P. J., P. Soto, and R. P. Natzke. 2004. Mastitis and fertility in cattle-Possible involvement of inflammation or immune activation in embryonic mortality. Am. J. Reprod. Immunol. 51:294-301.

Hertl, J. A., Y. T. Gröhn, J. D. Leach, D. Bar, G. J. Bennett, R. N. González, B. J. Rauch, F. L. Welcome, L. W. Tauer, and Y. H. Schukken. 2010. Effects of clinical mastitis caused by grampositive and gram-negative bacteria and other organisms on the probability of conception in New York State Holstein dairy cows. J. Dairy Sci. 93:1551-1560.

Hertl, J. A., Y. H. Schukken, F. L. Welcome, L. W. Tauer, and Y. T. Gröhn. 2014. Effects of pathogen-specific clinical mastitis on probability of conception in Holstein dairy cows. J. Dairy Sci. 97:6942-6954

Hockett, M. E., R. A. Almeida, N. R. Rohrbach, S. P. Oliver, H. H. Dowlen, and F. N. Schrick. 2005. Effects of induced clinical mastitis during preovulation on endocrine and follicular function. J. Dairy Sci. 88:2422-2431.

Hockett, M. E., F. M. Hopkins, M. J. Lewis, A. M. Saxton, H. H. Dowlen, S. P. Oliver, and F. N. Schrick. 2000. Endocrine profiles of dairy cows following experimentally induced clinical mastitis during early lactation. Anim. Reprod. Sci. 58:241-251.

Hogan, J., and K. L. Smith. 2003. Coliform mastitis. Vet. Res. 34:507519.

Huszenicza, G., S. Janosi, M. Kulcsar, P. Korodi, J. Reiczigel, L. Katai, A. R. Peters, and F. De Rensis. 2005. Effects of clinical mastitis on ovarian function in post-partum dairy cows. Reprod. Domest. Anim. 40:199-204.

Lavon, Y., E. Ezra, G. Leitner, and D. Wolfenson. 2011a. Association of conception rate with pattern and level of somatic cell count elevation relative to time of insemination in dairy cows. J. Dairy Sci. 94:4538-4545.

Lavon, Y., M. Kaim, G. Leitner, D. Biran, E. Ezra, and D. Wolfenson. 2016. Two approaches to improve fertility of subclinical mastitic dairy cows. J. Dairy Sci. 99:2268-2275.

Lavon, Y., G. Leitner, E. Klipper, U. Moallem, R. Meidan, and D. Wolfenson. 2011b. Subclinical, chronic intramammary infection lowers steroid concentrations and gene expression in bovine preovulatory follicles. Domest. Anim. Endocrinol. 40:98-109.

Lavon, Y., G. Leitner, H. Voet, and D. Wolfenson. 2010. Naturally occurring mastitis effects on timing of ovulation, steroid and gonadotrophic hormone concentrations, and follicular and luteal growth in cows. J. Dairy Sci. 93:911-921.

Levison, L. J., E. K. Miller-Cushon, A. L. Tucker, R. Bergeron, K. E. Leslie, H. W. Barkema, and T. J. DeVries. 2016. Incidence rate of pathogen-specific clinical mastitis on conventional and organic Canadian dairy farms. J. Dairy Sci. 99:1341-1350.

Lundberg, Å., A. Nyman, H. E. Unnerstad, and K. P. Waller. 2014 Prevalence of bacterial genotypes and outcome of bovine clinical mastitis due to Streptococcus dysgalactiae and Streptococcus uberis. Acta Vet. Scand. 56:80-91.

McDougall, S., T. J. Parkinson, M. Leyland, F. M. Anniss, and S. G. Fenwick. 2004. Duration of infection and strain variation in Strep- 
tococcus uberis isolated from cows' milk. J. Dairy Sci. 87:20622072.

Moore, D. A., J. S. Cullor, R. H. Bondurant, and W. M. Sischo. 1991 Preliminary field evidence for the association of clinical mastitis with altered interestrus intervals in dairy cattle. Theriogenology $36: 257-265$.

Østerås, O., L. Sølverød, and O. Reksen. 2006. Milk culture results in a large Norwegian survey-Effects of season, parity, days in milk, resistance, and clustering. J. Dairy Sci. 89:1010-1023.

Pyörälä, S., and S. Taponen. 2009. Coagulase-negative staphylococciemerging mastitis pathogens. Vet. Microbiol. 134:3-8.

Santos, J. E., R. L. Cerri, M. A. Ballou, G. E. Higginbotham, and J. H. Kirk. 2004. Effect of timing of first clinical mastitis occurrence on lactational and reproductive performance of Holstein dairy cows. Anim. Reprod. Sci. 80:31-45.

Schrick, F. N., M. E. Hockett, A. M. Saxton, M. J. Lewis, H. H. Dowlen, and S. P. Oliver. 2001. Influence of subclinical mastitis during early lactation on reproductive parameters. J. Dairy Sci. 84:1407-1412.

Schukken, Y. H., D. J. Wilson, F. Welcome, L. Garrison-Tikofsky, and R. N. Gonzalez. 2003. Monitoring udder health and milk quality using somatic cell counts. Vet. Res. 34:579-596.
Seegers, H., C. Fourichon, and F. Beaudeau. 2003. Production effects related to mastitis and mastitis economics in dairy cattle herds. Vet. Res. 34:475-491.

Sheldon, I. M., J. Cronin, L. Goetze, G. Donofrio, and H. J. Schuberth. 2009. Defining postpartum uterine disease and the mechanisms of infection and immunity in the female reproductive tract in cattle. Biol. Reprod. 81:1025-1032.

Soto, P., R. P. Natzke, and P. J. Hansen. 2003. Identification of possible mediators of embryonic mortality caused by mastitis: Actions of lipopolysaccharide, prostaglandin $\mathrm{F}_{2 \alpha}$, and the nitric oxide generator, sodium nitroprusside dihydrate, on oocyte maturation and embryonic development in cattle. Am. J. Reprod. Immunol. $50: 263-272$

Thatcher, W. W., and C. J. Wilcox. 1973. Postpartum estrus as an indicator of reproductive status in the dairy cow. J. Dairy Sci $56: 608-610$

Vakkamäki, J., S. Taponen, A. M. Heikkilä, and S. Pyörälä. 2017. Bacteriological etiology and treatment of mastitis in Finnish dairy herds. Acta Vet. Scand. 59:33-41.

Wang, S. M., M. A. Deighton, J. A. Capstick, and N. Gerraty. 1999 Epidemiological typing of bovine streptococci by pulsed-field gel electrophoresis. Epidemiol. Infect. 123:317-324. 